\title{
Reprodução das aves marinhas nas ilhas costeiras de Santa Catarina, Brasil
}

\author{
Joaquim Olinto Branco
}

Centro de Ciências Tecnológicas da Terra e do Mar, Universidade do Vale do Itajaí. Caixa Postal 360, 88301-970 Itajaí, Santa Catarina, Brasil. E-mail: branco@cttmar.univali.br

\begin{abstract}
Reproduction of the seabirds in Santa Catarina's coastal islands, Brazil. Studies involving the reproduction of seabirds in the Santa Catarina coast are scarce. From 1996 to 2002 a sampling program was implanted with the objectives of identifying the ranches, the species and to study some aspects of their reproductive cycle. Five species: Sula leucogaster Boddaert, 1783; Fregata magnificens Matheus, 1914; Larus dominicanus Lichtenstein, 1823; Sterna hirundinacea Lesson, 1831; S. eurygnatha Sauders, 1876, breed in the islands of Santa Catarina, with the largest intensity in the period of May to December. The size of the colonies varied in function of the species and of the reproduction area.
\end{abstract}

KEY WORDS. Avifauna, reproductive activity, seabirds ecology.

Estudos enfocando a reprodução das aves marinhas no litoral brasileiro são raros quando comparados aos das espécies continentais. Em função da infraestrutura com que conta a maioria dos ornitólogos marinhos para enfrentar as adversidades do mar, além da ausência de atracadouros para o reabastecimento da equipe, abrigos e a morosidade na liberação das permissões de permanência, comprometem o acesso e monitoramento periódico das colônias de aves nas ilhas de nidificação.

Mesmo assim, alguns pesquisadores têm contribuído direta ou indiretamente para o conhecimento da reprodução das aves marinhas insulares brasileiras: Novaes (1952), Oren (1982), Bege \& Pauli (1988), Antas (1991), Soares \& Schiefler (1995), Sick (1997), Alves et al. (1997), EFe et al. (2000).

Apesar dos $670 \mathrm{~km}$ de litoral catarinense e a existência de cerca de 255 ilhas, ilhotes, parcéis e lajes, existem apenas os trabalhos de Bege \& Pauli (1988) nas Ilhas Moleques do Sul (Florianópolis), onde registraram aspectos do ciclo de vida dos Sulidae, Fregatidae e Laridae e o de SoAres \& Schiefler (1995), que realizaram levantamento das aves marinhas da Ilhota da Galheta (Laguna).

Apesar da deficiência de informações na literatura científica, é consenso entre pescadores e pesquisadores que os Pelecaniformes (atobás, fragatas) e Charadriiformes (gaivotas, trinta-réis), utilizam as ilhas costeiras como local de nidificação e abrigo (BRANCO 1999).

Devido á carência de informações sobre a reprodução das aves marinhas em Santa Catarina, este trabalho tem como objetivo contribuir para o conhecimento de aspectos do ciclo reprodutivo dessas aves nas ilhas costeiras do estado.

\section{MATERIAL E MÉTODOS}

\section{Áreas Estudadas}

Arquipélago de Tamboretes: composto pelas Ilhas do Norte, do Porto, do Meio, Rema (Ilha dos Pássaros) e do Sul; está localizado entre as coordenadas $26^{\circ} 22^{\prime} 10^{\prime \prime}-26^{\circ} 23^{\prime} 36^{\prime \prime} \mathrm{S}$; $48^{\circ} 31^{\prime} 11^{\prime \prime}-48^{\circ} 31^{\prime} 33^{\prime \prime} \mathrm{W}$ e distam entre 4,5 a $5,0 \mathrm{~km}$ da costa (Fig. 1). As amostragens foram realizadas mensalmente, durante o período de julho/2000 a dezembro/2002. O próximo sítio de reprodução de aves marinhas ao sul, é formado pelas Ilhas Itacolomis a 37,6 km de distância.

Ilhas Itacolomis: localizadas na Armação do Itapocoroy (Penha), entre as coordenadas $26^{\circ} 42^{\prime} 36^{\prime \prime} \mathrm{S}$ e $48^{\circ} 37^{\prime} 06^{\prime \prime} \mathrm{W}$, formadas por dois promontórios rochosos em forma de cone, recobertas no topo por gramíneas e vegetação arbustiva, com altura aproximada entre 25 a $35 \mathrm{~m}$, sendo separadas por um canal com $12 \mathrm{~m}$ de largura (Fig.1). As amostragens foram realizadas mensalmente, durante o período de julho/1996 a dezembro/2002. A próxima área ao sul é formada pela Ilha Deserta a $68,5 \mathrm{~km}$ desta.

Ilha Deserta: pertence à Reserva Biológica Marinha do Arvoredo (RBMA) foi criada em março de 1990 pelo Decreto Federal $\mathrm{n}^{\circ} 99.142 / 90$, estando distante cerca de $11 \mathrm{~km}$ ao norte da Ilha de Florianópolis. A RBMA é um arquipélago formado pelas ilhas do Arvoredo, Galé, Deserta e Calhau de São Pedro, incluindo toda a faixa marinha que as circundam (IBAMA, 1996). A Ilha Deserta é o principal sítio de reprodução das aves marinhas nesse arquipélago, e está localizada entre as coordenadas $27^{\circ} 16^{\prime} 23^{\prime \prime} \mathrm{S}$ e $48^{\circ} 19^{\prime} 53^{\prime \prime} \mathrm{W}$. As amostragens foram reali- 


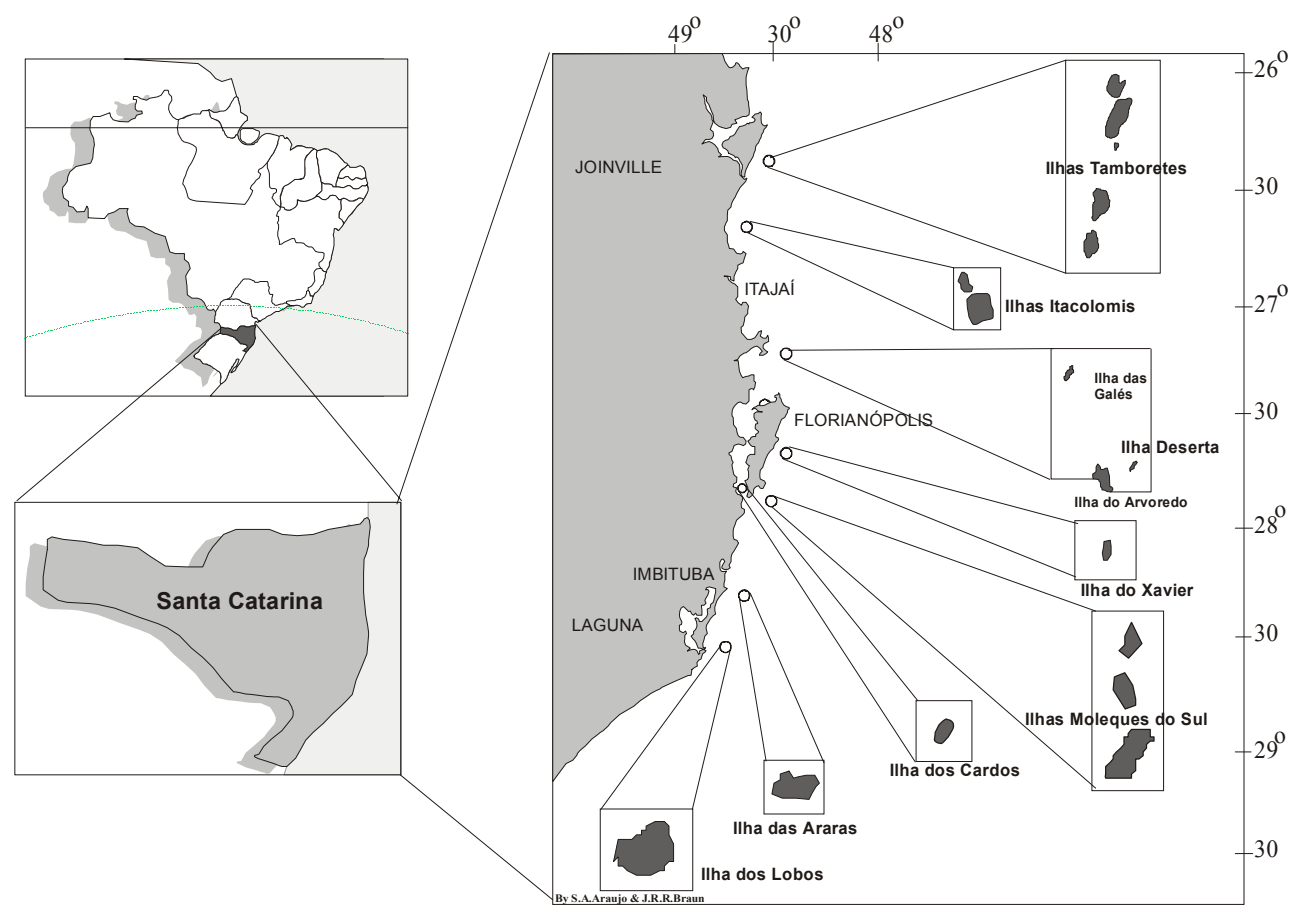

Figura 1. Mapa indicando a localização das ilhas estudadas.

zadas mensalmente, durante o período de novembro/1998 a setembro/2000 e de junho a dezembro/2002. O próximo sítio de nidificação ao sul, de reconhecida importância, são as ilhas Moleques do Sul, que está a 64,3 km de distância.

Ilhas Moleques do Sul: considerado o principal sítio de reprodução das aves marinhas da costa catarinense; pertencem ao Parque Estadual da Serra do Tabuleiro. Esse Arquipélago é composto por três ilhas situadas entre as coordenadas $27^{\circ} 51^{\prime} \mathrm{S}$ e $48^{\circ} 26^{\prime} \mathrm{W}$, aproximadamente $12 \mathrm{~km}$ da praia do Pântano do Sul ao sul de Florianópolis (Fig. 1). As amostragens foram realizadas mensalmente, durante o período de junho/2000 a dezembro/2002. O próximo local ao sul é formado pela Ilha dos Lobos, que está a 71,9 km de distância.

Ilha dos Lobos: (Laguna) localizada entre as coordenadas: $28^{\circ} 26^{\prime} 50^{\prime \prime} \mathrm{S}$ e $48^{\circ} 42^{\prime} 37^{\prime \prime} \mathrm{W}$ (Fig. 1). Essa ilha apresenta-se destituída de gramíneas, com reduzidas manchas de arbustos e algumas árvores. Os coelhos introduzidos pelos pescadores locais consumiram a vegetação, normalmente empregada na construção dos ninhos das gaivotas. Atualmente, restos de caules, raízes e fragmentos de rochas são únicos materiais encontrados nos ninhos. O défice de gramíneas tem contribuindo na destruição dos ninhos pelas enxurradas. Além disso, a colônia é constantemente perturbada pelos caçadores de coelhos e coletas esporádicas de ovos. As amostragens foram realizadas mensalmente, durante o período de julho a dezembro/2002.

Ilha dos Cardos: ilhota localizada na extremidade sul da Baía Sul (Fig. 1) $\left(27^{\circ} 48^{\prime} 55^{\prime \prime}\right.$ S e $\left.48^{\circ} 34^{\prime} 52^{\prime \prime} \mathrm{W}\right)$, entre as localidade de Ribeirão da Ilha (Florianópolis) e Praia da Pinheira (Palhoça). Apesar da sua extensão e proximidade com a população humana, esse sítio é um importante local de nidificação para Sterna hirundinacea Lesson, 1831; S. eurygnatha Sauders, 1876 , estando aproximadamente a $13 \mathrm{~km}$ ao sul das Ilhas Moleques do Sul.

\section{Métodos}

A cada mês, foi realizada uma visita nas ilhas acima mencionadas (Fig. 1), onde foram executadas as seguintes rotinas de trabalho: identificação das aves marinhas por meio de observação direta utilizando de Binóculos Bushnell (10x50) estimado o tamanho das colônias em nidificação em número de pares reprodutores, registrado o número de ovos por ninho, o período de reprodução em cada ilha e os potenciais predadores.

\section{RESSULTADOS E DISCUSSÃO}

De acordo com a figura 2, cinco espécies de aves marinhas nidificam nas ilhas do litoral de Santa Catarina: Sula leucogaster (Boddaert, 1783); Fregata magnificens Mathews, 1914; Larus dominicanus Lichtenstein, 1823; Sterna hirundinacea Lesson, 1831; S. eurygnatha Sauders, 1876.

\section{Sterna hirundinacea e $S$. eurygnatha (Trinta-réis)}

O período reprodutivo de $S$. hirundinacea no litoral catarinense, estendeu-se entre os meses de abril a outubro e $S$. eurygnatha de maio a outubro (Fig. 2), em ninhos construídos no solo e forrados com gramíneas.

Sterna hirundinacea é a única espécie de trinta-réis que nidificou regularmente de 1996 a 2002 nas Ilhas Itacolomis, entre os meses de abril a setembro, mantendo uma população 


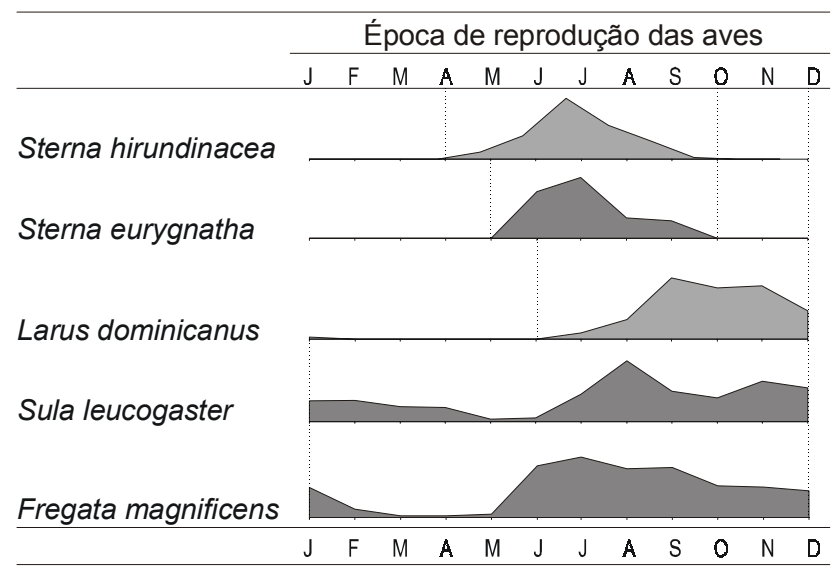

Figura 2. Período de reprodução das aves marinhas insulares no litoral de Santa Catarina.

estável, entre 250 a 280 casais e um sucesso reprodutivo em torno de 63,0 a $68,0 \%$. A reduzida pressão antrópica nas ilhas e a baixa ação de predadores naturais sobre a colônia como Larus dominicanus, durante o período de postura dos ovos e desenvolvimento dos jovens, alheada à oferta constante de alimento oriundo da pesca artesanal de camarões (BRANCO 2001), permitiu a ocupação regular desse sítio.

$\mathrm{Na}$ Ilha Deserta, os primeiros exemplares de $S$. hirundinacea foram observados a partir de abril, após o início da postura dos ovos; em maio ocorreu a chegada e ocupação do centro da colônia por $S$. eurygnatha, sendo as duas espécies monitoradas em 1999, 2000 e 2002 . No primeiro ano, a colônia mista foi formada por 500 casais de $S$. hirundinacea e 65 de $S$. eurygnatha, não conseguiu resistir a predação das gaivotas $L$. dominicanus, causando o abandono da ilha no início de agosto, com a sobrevivência de apenas oito jovens de $S$. hirundinacea. No segundo e terceiro anos, as duas espécies retornaram à ilha com um contingente menor de reprodutores; após a postura dos ovos entre maio e junho ocorreu o abandono da área devido a predação total dos ninhos pelas gaivotas.

A colônia mista monitorada nas Ilhas Moleques do Sul em 2000, esteve formada por aproximadamente 1200 casais de $S$. hirundinacea e 200 S. eurygnatha; apesar da pressão de $L$. dominicanus e dos gaviões Polyborus plancus (Miller, 1777), Rupornis magnirostris (Gmelin, 1788), foi registrado um considerável sucesso reprodutivo, em torno de $34,1 \%$ para $S$. hirundinacea e 24,5 para S. eurygnatha, com o abandono da ilha após o término do período reprodutivo. Nos anos seguintes, não ocorreu a ocupação das ilhas pelos trinta-réis.

Em setembro de 2001 foi encontrada uma colônia mista de reprodução na Ilha dos Cardos, com aproximadamente 230 casais de $S$. hirundinacea e 30 de $S$. eurygnatha. De acordo com os pescadores do Ribeirão da Ilha, Florianópolis, nunca havia sido observado aves marinhas nidificando na ilha. Nesse ano foram efetuadas apenas duas visitas à colônia em setembro. Em 2002 foi monitorado mensalmente a colônia mista, sendo registrado um incremento no número de reprodutores, passando para 268 pares de $S$. hirundinacea e 76 de $S$. eurygnatha. Embora não tenha ocorrido reprodução de $L$. dominicanus na ilha, foi registrada a presença de quatro a seis exemplares, que constantemente eram expulsos pelos trinta-réis, mas a presença ocasional de um casal de caracará (P. plancus), casou mortandade de alguns jovens e adultos.

Os trinta-réis apresentam diferentes estratégias de reprodução; enquanto que $S$. hirundinacea nidificou nas bordas da colônia, investindo em posturas com um a três ovos por ninho, $S$. eurygnatha, de maior porte e agressividade, depositou apenas um ovo por ninho no centro da colônia. Independente da espécie, os ninhos com um ovo dominaram nas colônias. Nas Ilhas Moleques do Sul foi registrado o maior número médio de ovos de $S$. hirundinacea por postura $(1,44 \pm 0,54)$, enquanto que nos ninhos da Ilha Deserta ocorreram as menores médias $(1,22 \pm 0,51)$.

\section{Larus dominicanus (Gaivota)}

No período de março a junho ocorreu o deslocamento das gaivotas adultas para as ilhas, demarcação de território e construção dos ninhos no solo, utilizando-se gramíneas, penas e até ossos de outras aves. Os primeiros ninhos com ovos foram observados em junho, incrementando gradativamente até setembro, seguido de redução em outubro e ausência das gaivotas a partir de dezembro (Fig. 2), ocorrendo a ocupação dos estuários e das praias do litoral catarinense (BRANCO \& EBERT 2002); entretanto, alguns adultos e jovens puderam ser encontrados nas ilhas Moleques do Sul e Ilha dos Lobos até o início de janeiro. Em Punta Leon, Argentina, os primeiros ninhos de L. dominicanus com ovos ocorreram entre 10 a 12 de outubro e os filhotes a partir de novembro (Yorio et al. 1995).

O número de reprodutores por ilha oscilou ao longo dos anos. Em torno de 280 casais nidificaram nas Ilhas Tamboretes, 76 em Itacolomis, 497 na Deserta, 177 em Moleques do Sul e 680 na Ilha dos Lobos. O tamanho da postura variou entre um e três ovos por ninho, sendo a média nas Ilhas Moleques

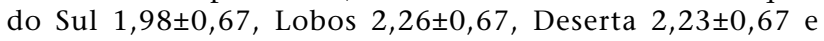
Itacolomis 2,19 $\pm 0,74$; acima de $54,0 \%$ dos ninhos encontrados nessa ilhas possuíam dois ovos. Embora em Tamboretes $(2,21 \pm 0,78)$ foi observado esse predomínio, a freqüência de ninhos com dois ovos ficou em torno de $36,1 \%$. De acordo com Malacalza (1987) entre 42 a $49 \%$ dos ninhos de $L$. dominicanus em Punta Leon continham dois ovos. Para Yorio et al. (1995) o número médio de ovos por ninho de gaivota variou entre 2,32 a 2,39, enquanto que na Ilhota da Galheta (Laguna), a média por ninho foi de 2,3 ovos (SoARes \& SCHIEFLer 1995). Provavelmente, essas diferenças estão relacionadas com o esforço reprodutivo em cada sítio e com a condições fisiológicas das populações, assim como recursos ecológicos disponíveis.

\section{Sula leucogaster (Atobá-marrom)}

O atobá-marrom nidificou durante todo o ano nas Ilhas Moleques do Sul, limite austral de ocorrência de colônias de reprodução, sendo que a maioria dos ninhos com ovos foi observada em agosto (Fig. 2) e entre junho a fevereiro nas Ilhas Tamboretes. Os ninhos são construídos no solo, sendo freqüente a inclusão de penas, gravetos secos, ossos de outras aves e, ainda, ramos de vegetação próxima com folhas verdes, em ninhos cuja incubação está em andamento. Durante esse período e nas fases iniciais dos filhotes, os adultos responderam com agressividade às incursões de indivíduos da sua espécie, de outras aves ou de pesquisadores no seu território. 
O Tamanho da colônia oscilou entre 265 casais que nidificaram nas Ilhas Moleques do Sul e 65 em Tamboretes. Os ninhos com um ovo corresponderam entre 54,1 a $68,4 \%$ do esforço reprodutivo nas áreas amostradas, com dois ovos entre 45,6 a $31,6 \%$ e, com três, apenas $0,3 \%$. O número médio de ovos por ninho de atobá variou entre 1,52 $\pm 0,49$ (Tamboretes) a 1,57 $\pm 0,49$ (Moleques do Sul).

Em geral, S. leucogaster investiu em uma postura com um, dois e raramente com três ovos, mas criou apenas um filhote. Esse fato, tem suscitado uma interessante discussão entre os pesquisadores. Para autores como Tershy et al. (2000), NeLson (1980) e Doward (1962), o segundo funciona como "ovo de segurança". Caso o primeiro ovo ou filhote não se desenvolva, o processo reprodutivo terá continuidade. O primeiro ovo é posto, em média, com cinco dias de diferença do segundo (DOWARD 1962). Esse assincronismo no atobá-marrom induz ao fraticídio, gerado pela condição hierárquica entre os irmãos (TERSHY et al. 2000).

\section{Fregata magnificens (Fragatas)}

É uma espécie de ampla distribuição geográfica; no Brasil são encontradas colônias em Fernando de Noronha, Bahia, Rio de Janeiro, São Paulo, Paraná e Santa Catarina (SıCK 1997). As Ilhas Moleques dos Sul é o limite austral de ocorrência de colônia de reprodução e o único sítio de nidificação no Estado. Os ninhos, em geral, são construídos sobre arbustos e árvores, com gravetos retirados do local e compactados com as próprias fezes. A fragata coloca apenas um ovo de cor branca, que é incubado por aproximadamente 40 a 45 dias em turnos alternados pelo casal.

Em torno de 540 a 600 casais de F. magnificens nidificaram por temporada nas Ilhas Moleques do Sul. A reprodução ocorreu ao longo do ano, com predomínio entre junho a setembro (Fig. 2). Bege \& PAULI (1988), também confirmam a ocorrência anual das fragatas nessas ilhas, tendo os meses entre junho e agosto como início do período reprodutivo e a maioria das eclosões dos filhotes entre novembro e dezembro.

\section{Ilhas não monitoradas}

A Ilha do Xavier está localizada entre as Ilhas Moleques do Sul e Deserta, aproximadamente a $3 \mathrm{~km}$ da Praia Molhe (Florianópolis) (Fig. 1). É informalmente apontada como um local de nidificação de $L$. dominicanus, mas não existem informações disponíveis que confirmem o relato.

Na Ilha das Araras (Imbituba), a aproximadamente 60 $\mathrm{km}$ ao sul de Moleques do Sul (Fig. 1), foi encontrada em agosto/2002, uma colônia de L. dominicanus nidificando com aproximadamente 100 casais. Nas décadas de 50 a 80 era um hábito comum a coleta de ovos dos trinta-réis nessa ilha, o que pode ter levado ao abandono desse sítio pela ação antrópica. Além disso, hoje a ilha abriga algumas cabras e coelhos introduzidos pelos pescadores locais, o que vem modificando a vegetação e danificando os ninhos das gaivotas.

A Ilha da Galheta (Laguna) distante em direção ao sul, aproximadamente $20 \mathrm{~km}$ da Ilha dos Lobos, pode ser considerado o último sítio de reprodução das aves marinhas no litoral catarinense. De acordo com Sodres \& Schiefler (1995), nidificaram em torno de quatro casais de Piru-piru (Haematopus palliatus Temminck, 1820), 107 de L. dominicanus. Esses autores, atribuíram o fracasso total dos 207 ninhos de $S$. hirundinacea encontrados na ilha, à possível coleta dos ovos por pescadores e turistas que visitam o local.

\section{Predadores}

Os principais sítios de reprodução das aves marinhas insulares no litoral de Santa Catarina estão livres de mamíferos predadores; entretanto, a pressão dos urubus e gaviões continentais pode ser considerada acentuada, sendo que em cada uma das ilhas estudadas foi possível encontrar de duas a quatro espécies de predadores.

O urubu Coragyps atratus (Bonaparte, 1850) foi o predador mais abundante, ocorrendo ao longo do ano e nidificando na maioria das ilhas entre os meses de setembro a dezembro. Sua atuação foi maior sobre os ovos e filhotes das aves que nidificam no solo, como atobás, gaivotas e trinta-réis e, em menor freqüência, sobre as espécies que constroem ninhos nas árvores, como as fragatas. O caracará (P. plancus) atuou preferencialmente sobre filhotes e adultos de trinta-réis. Na ausência destes, predam os jovens das gaivotas e atobás. Foi observado apenas um casal que reproduziu entre setembro e meados de novembro nas Ilhas Tamboretes e Moleques do Sul. Os gaviões carijó (R. magnirostris) e carrapateiro (Milvago chimachima (Vieillot, 1816)), predaram principalmente os filhotes recémnascidos das gaivotas e atobás nas Ilhas Moleques do Sul.

Os atobás das Ilhas Moleques do Sul e Tamboretes construíram seus ninhos em áreas de uso comum com as gaivotas, o que resultou em grande predação de ovos e filhotes recémeclodidos dos casais que não defendiam eficientemente seus ninhos ou que estavam nidificando pela primeira vez.

De acordo com Yorio et al. (1994) e SoAres \& SCHIEfLer (1995), a escolha do local de reprodução de $S$. hirundinacea e $S$. eurygnatha, pode mudar de um ano para outro, sendo freqüente o abandono em massa das áreas de reprodução diante de qualquer tipo de distúrbio. A gaivota L. dominicanus representou a maior ameaça para as colônias mistas de trinta-réis e atobás no litoral catarinense. Quando a pressão é intensa sobre colônias relativamente pequenas de $S$. hirundinacea e $S$. eurygnatha, como o registrado em 1999, 2000 e 2002 na Ilha Deserta, ela pode acarretar a perda total dos ovos e filhotes, levando o abandono da área de reprodução e a alternância dos sítios de nidificação entre os anos.

\section{REFERÊNCIAS BIBLIOGRÁFICAS}

Alves, V.S.; A.B.A. Soares; G.S. Couto; A.B.B. Ribeiro \& M.A. Efe. 1997. Aves do Arquipélago dos Abrolhos, Bahia, Brasil. Ararajuba 5 (2): 209-218.

Bege, L.A.R. \& B.T. PAuli. 1988. As aves nas Ilhas Moleques do Sul - Santa Catarina: Aspectos da ecologia, etologia e anilhamento de aves marinhas. Florianópolis. FATMA, $64 \mathrm{p}$.

Branco, J.O. 2001. Descartes da pesca do camarão sete-barbas como fonte de alimento para aves marinhas. Revista Brasileira de Zoologia, Curitiba, 18 (1): 293-300.

Branco, J.O. \& L.A. EBert. 2002. Estrutura populacional de Larus dominicanus Lichtenstein, 1823 no estuário do Saco da Fazenda, Itajaí, Santa Catarina, Brasil. Ararajuba, Londrina, 10 (1): 79-82.

DorWARD, D.F. 1962. Comparative biology of the white booby and the brown booby Sula spp. Atascension. Íbis, London, 103: $175-220$. 
Efe, M.A.; J.L.X. Nascimento; I.L.S. Nascimento \& C. Musso. 2000. Distribuição e ecologia reprodutiva de Sterna sandvicensis eurygnatha no Brasil. Melopsittacus, Belo Horizonte, 3 (3): 110-121.

Malacalza, V.E. 1987. Aspectos de la biologia reproductiva de la gaviota cocinera Larus dominicanus Lichtenstein, en Punta Leon (Chubut, Argentina). Physis, Secc. C, 45 (108): 11-17.

Nelson, J.B. 1980. Seabirds - Their Biology and Ecology. London, Hamlyn Publishing Group, 224p.

NOVAES, F.C. 1952. Resultados ornitológicos da "Expedição João Alberto" à Ilha de Trindade. Revista Brasileira de Biologia, Rio de Janeiro, 12: 219-228.

Oren, D.C. 1982. Avifauna do Arquipélago de Fernando de Noronha. Boletim Museu Paraense Emílio Goeldi, Belém, 118: $1-21$.
SICK, H. 1997. Ornitologia Brasileira. Rio de Janeiro, Editora Nova Fronteira, 912p.

SoAres, M. \& A.F. Schiefler. 1995. Aves da Ilhota da Galheta, Laguna, SC, Brasil. Arquivos de Biologia e Tecnologia, Curitiba, 38 (4): 1101-1107.

Tershy, B.R.; D. Breese \& D.A. Croll. 2000. Insurance eggs additional eggs: the brown boobies practice obligate siblicide? Auk 117 (3): 817-820.

Yorio, P.; F. Quintana; C. CAMPagna \& G. Harris. 1994. Diversidad, abundancia y dinamica espacio-temporal de la colonia mixta de aves marinas en Punta Leon, Patagonia. Ornitologia Neotropical 6 (2): 69-77.

Yorio, P.; M. Bertellotti \& F. Quintana. 1995. Preference for covered nest sites and breeding success in Kelp Gulls Larus dominicanus.Marine Ornithology 23: 121-128.

Recebido em 22.IV.2003; aceito em 21.X.2003. 